\title{
Aspartic Acid as Corrosion Inhibitor of Mild Steel Corrosion Using Weight Loss, Acidimetry and EIS Measurement
}

\author{
${ }^{1}$ Sylvester Obaike Adejo, ${ }^{2}$ Stephen Gbaoron Yiase, ${ }^{3}$ Joseph Aondoaver Gbertyo and ${ }^{4}$ Emmanuel Onah Ojah \\ 1,283Benue State University, Makurdi-Nigeria P.M.B 102119 \\ ${ }^{4}$ University of Ibadan, Ibadan-Nigeria \\ *Corrsesponding Author: ja.gbertyo@gmail.com phone: +2348062919604 \\ 1soadejo@gmail.com 2sgyiase@yahoo.com ${ }^{4}$ emmanuel.ojah@yahoo.com
}

\begin{abstract}
Corrosion inhibition characteristics of aspartic acid on mild steel corrosion in $0.5 \mathrm{M} \mathrm{H}_{2} \mathrm{SO}_{4}$ was investigated using weight loss, acidimetry, and electrochemical impedance spectroscopy (EIS). Analysis of the metal surface morphology, uninhibited and inhibited, was carried out through scanned electron microscope. The results showed that the inhibition efficiency increased with increase in inhibitors concentration and rise in temperature for all methods used. The highest v efficiency of $32.36 \%, 66.26 \%$ and $80.40 \%$ were obtained for weight loss, acidimetry and EIS, respectively. The low value of efficiency for weight loss compared to other methods should signify the limitation for the method. The increase in efficiency with rise in temperature is a feature of chemical adsorption, which was confoirmed by the value of parameter $b$ of the Adejo-Ekwenchi adsorption isotherm (AEI) model. Values of free energy of adsorption, $\Delta G_{\text {ads }}$ were all negative for all the methods, which means the adsorption processes were spontaneous. The heats of adsorption, $Q_{a d s}$ values were all positive, implying that the processes were endothermic. Values of activation energy were fairly constant, which is an evident to support the proposed chemical adsorption mechanism. The negative sign in the values of entropy of adsorption, $\Delta \mathrm{S}_{\text {ads }}$ is an indication that the activated complex in the rate-determining step was associative. The data obtained was tested with several isotherms, but found to best fit into the El-Awady, Freundlich and Tempkin adsorption isotherm models.
\end{abstract}

Indexing terms/Keywords: EIS, Aspartic acid, weight loss, acidimetry, corrosion inhibition

Subject Classification: Chemistry

Type (Method/Approach): Laboratory Research

\section{Introduction}

All natural processes tend toward the lowest possible energy states and every metal is embedded with a certain natural potential, such that those with high potentials (more negative) would have to anodically release corrosion current when coupled with those of lower (less negative) energies. Controlling the rate at which this process occurs has been the greatest challenge faced by corrosion chemists and material science engineers. Corrosion of engineering structures and components in service has become a huge source of concern to corrosion experts in the academia and industries. This is primarily due to its deleterious effect on material integrity and mechanical properties resulting to failure in severe cases [1]. A study conducted in 2002 estimated an expenditure of $3.1 \%$ of GDP as the cost of addressing corrosion related problems by the US economy [2]. Considering the huge cost of corrosion monitoring and control, a great deal of efforts has been channeled towards developing technically efficient and cost-effective strategies for corrosion management [3]. The use of corrosion inhibitors has been very promising particularly with the use of non-toxic materials. Such inhibitors offer a number of advantages such as biodegradability, absence of heavy metals or other toxic compounds, availability and ease of processing.

It is practically impossible to stop a natural event but it is feasible to design methods to alter such processes. In order to mitigate corrosion several techniques have to be developed [4]. The most common are application of 
coatings, anodic and cathodic protections, $\mathrm{pH}$ change, alloying and use of inhibitors [5]. A corrosion inhibitor is any substance, which when added to a corrosive environment in small amount reduces the corrosion rate of a material [6-9]. We have two main class of inhibitors; organic and inorganic. Organic inhibitors minimize corrosion by mainly by adsorption while inorganic inhibitors arrest corrosion situations by interfering with either the anodic or cathodic regions of the corrosion process $[10,11]$.

Despite the increasing amount of work done on developing new corrosion inhibitors to substitute the carcinogenic and genotoxic hexavalent chromium-based ones, no clear substitute has been found yet. In 1980s, rare earth based corrosion inhibitors were highlighted as potentially most relevant [12] and studies have focused mainly on understanding the effect of the rare earth ion (mostly cerium) in corrosion protection [13]. Below in equation (1) represents a simple corrosion process for the rusting of iron in an oxygen environment in the absence of moisture;

$4 \mathrm{Fe}(\mathrm{s})+3 \mathrm{O}_{2}(\mathrm{~g}) \rightarrow 2 \mathrm{Fe}_{2} \mathrm{O}_{3}(\mathrm{~s})$

The above reaction takes place at the surface of iron. Corrosive attack on metals generally occurs only at the surface and any modification of such surfaces or the environment can change the rate of the reaction. This is therefore the basis of corrosion protection [14]. In this work we undertook the study of corrosion inhibition of mild steel in $0.5 \mathrm{M} \mathrm{H}_{2} \mathrm{SO}_{4}$ using of an amino acid (aspartic acid) as a corrosion inhibitor by three different methods: weight loss, acidimetry, and electrochemical impedance spectroscopy.

\section{Materials and Methods}

Mild steel rods were procured and taken to the Department of Mechanical Engineering, University of Agriculture, Makurdi-Nigeria, where they were mechanically press-cut to form different coupons, each of dimensions $2.0 \times$ $2.0 \times 0.35 \mathrm{~cm}$ with a tiny hole drilled at the edge of each for the purpose of suspension in the corrodant. The surfaces of the coupons were thoroughly polished to mirror finish using sand paper, degreased by washing with ethanol, dried with acetone, and preserved in a desiccator. Subsequently, the coupons were weighed and made ready for analysis. All reagents used were of analytical grade and the water used for preparation was distilled [1-7].

\subsection{Weight loss measurement}

The method adopted was that reported by many scholars [3-7] and represented by equation (2) below,

$W=W_{i}-W_{f}$

where $W$ is the weight loss of the coupon, $W_{i}$ the initial weight and $W_{f}$ the weight after retrieval. Each reading reported is an average of three experimental readings recorded to the nearest $0.001 \mathrm{~g}$. The inhibition efficiency was calculated using the formula as represented by equation (3).

$$
\% \text { I.E }=\left[1-\frac{W_{1}}{W_{2}}\right] \times 100
$$

where $W_{1}$ and $W_{2}$ are the weight losses (in grams) of mild steel coupon in the presence and absence of the inhibitor in the acid solution at the same temperature. The degree of surface coverage, $\theta$, was evaluated by the equation (4) [6-9].

$$
\theta=1-\frac{W_{1}}{W_{2}}
$$

The corrosion rate of the mild steel coupons was determined for the immersion period from weight loss using equation (5).

$$
\text { Corrosion rate }\left(\mathrm{mg} / \mathrm{cm}^{2} / \mathrm{h}\right)=\frac{\mathrm{W}_{\mathrm{L}}}{A t}
$$

where $W_{L}$ is the weight loss in milligrams $(\mathrm{mg}), A$ the coupon surface area in $\mathrm{cm}^{2}$ and $t$ the immersion time in hours [6]. Using an equation similar to the Arrhenius equation (equation 6 ), values of activation energy, $E_{a}$, were obtained [11].

$$
\ln C R=\ln A-\frac{E a}{R T}
$$


An alternative formula of transition state equation is given in equation (7).

$$
\ln \left(\frac{C R}{T}\right)=\ln \left(\frac{R}{N h}\right)+\frac{\Delta S^{*}}{R}-\frac{\Delta H^{*}}{R T}
$$

where $h$ is plank's constant, $N$ the Avogadro's number, $\Delta H^{*}$ is the enthalpy of activation and $\Delta S^{*}$ the entropy of activation. A plot of $\ln \left(\frac{C R}{T}\right)$ versus $\frac{1}{T}$ gave a straight line with a slope of $-\frac{\Delta H^{*}}{R T}$ and an intercept of $\ln \left(\frac{R}{N h}\right)+\frac{\Delta S^{*}}{R}$ from where the values of $\Delta H^{*}$ and $\Delta S^{*}$ were calculated.

The heat of adsorption Qads was evaluated using equation (8) below.

$\log \left(\frac{\theta}{1-\theta}\right)=\log A+\log K-\frac{Q_{a d s}}{2.303 R}\left(\frac{1}{T}\right)$

where $\theta$ is the degree of surface coverage, $R$ is the molar gas constant, $T$ is the absolute temperature, and $A$ is a temperature independent factor. Values of heat of adsorption were obtained from the slope $\left(\frac{-Q_{a d s}}{2.303 R}\right)$ of a plot of $\log \left(\frac{\theta}{1-\theta}\right)$ against $\frac{1}{T}$.

Values of $\Delta \mathrm{G}_{\mathrm{ads}}$ were evaluated using equation (9), where $K=\frac{\theta}{(1-\theta) C}$

$\Delta G=-R T \ln (55.5 K)$

\section{The Acidimetric method}

The $\mathrm{pH}$ of the acid before insertion of coupons was taken using $\mathrm{pH}$ meter. The coupon was then immersed in $40 \mathrm{~mL}$ of the acid solution in a $50 \mathrm{~mL}$ beaker using a thread and allowed to stay unstirred for 7 hours at a temperature of $301 \mathrm{~K}$. After retrieval of the coupon the $\mathrm{pH}$ of the acid was taken again. The difference between the concentrations at the beginning and after the retrieval was evaluated and the values were related to the quantity of mild steel consumed by the acid during the corrosion process, from where the inhibition efficiency (equation 10) and the corrosion rate (equation 12) were evaluated.

\section{(a) Inhibition Efficiency}

Inhibition efficiency $I E=\left[1-\left(\frac{\left[\Delta H^{+}\right]_{\text {inh }}}{\left[\Delta H^{+}\right]_{\text {uninh }}}\right)\right] \times 100 \%$

where, $\left[\Delta H^{+}\right]_{\text {inh }}$ and $\left[\Delta H^{+}\right]_{\text {uninh }}$ are concentrations of the hydrogen ion in the presence and absence of inhibitor respectively.

(b) Surface Coverage: The surface coverage, $\theta$, was evaluated using equation (11) below;

$$
\theta=1-\left(\frac{\left[\Delta H^{+}\right]_{\text {inh }}}{\left[\Delta H^{+}\right]_{\text {uninh }}}\right)
$$

(c) Corrosion rate: The corrosion rate of mild steel sample was calculated using equation (12) below,

$$
C_{R}\left(\text { moldm }^{-3} \mathrm{~cm}^{-2} h^{-1}\right)=\frac{\left[\Delta H^{+}\right]}{A t}
$$

where $\left[\mathrm{SH}^{+}\right]$is the difference between the initial and final concentration of $\mathrm{H}^{+}, \mathrm{A}$ the surface area of the coupon in $\mathrm{cm}^{2}$ and $\mathrm{t}$, the time in hours.

\subsection{Electrochemical Impedance spectroscopy}

The inhibition processes of the inhibitors were also studied by electrochemical method. The electrochemical impedance spectroscopy (EIS) uses either the Nyquist plot or Bode plot. For the Nyquist equation, a graph of $Z_{\text {imag }}\left(\Omega \mathrm{cm}^{2}\right)$ against $Z_{\text {real }}\left(\Omega \mathrm{cm}^{2}\right)$ was plotted. Nyquist plots for mild steel at $301 \mathrm{~K}$ in the absence and at various concentrations of the inhibitor were made. Generally, the Nyquist plots are regarded as semicircles. These types of plots are modelled by a simple Randels circuit including the charge transfer resistance $\left(R_{c t}\right)$ parallel with double layer capacitance $\left(C_{d l}\right)$ in series with solution resistance $\left(R_{s}\right)$ [15]. The corrosion of mild steel is expected to decrease in the presence of the inhibitor because the charge transfer resistance, $R_{c t}$ of mild steel will significantly increase in the presence of the inhibitors. As the inhibitor concentration increases, the charge transfer resistance will increase and the value of constant phase element (CPE) will decrease. Increasing of charge transfer resistance with inhibitor concentration will suggest that more inhibitor molecules are adsorbed on the 
metal surface at higher concentration leading to greater surface coverage. Decrease in the CPE will be caused by reduction in local dielectric constant and/or by increase in the thickness of the electrical double layer. This fact suggests that the inhibitor molecules act by adsorption at the metal/solution interface [16]. The set up for EIS measurement is as showed in Figure 1.

In the case of the EIS studies, the inhibition efficiency $\left(\% \eta_{Z}\right)$ was be calculated using the charge transfer resistance as follows [16] in equation 13.

$$
\% \eta_{\mathrm{Z}}=\frac{\mathrm{R}_{\mathrm{ct}(\mathrm{inh})}-\mathrm{R}_{\mathrm{ct}(\text { uninh })}}{\mathrm{R}_{\mathrm{ct}(\mathrm{inh})}} \times 100
$$

where, $R_{c t(u n i n h)}$ is the charge transfer of the uninhibited and $R_{c t(i n h)}$ is that of the inhibited sample.

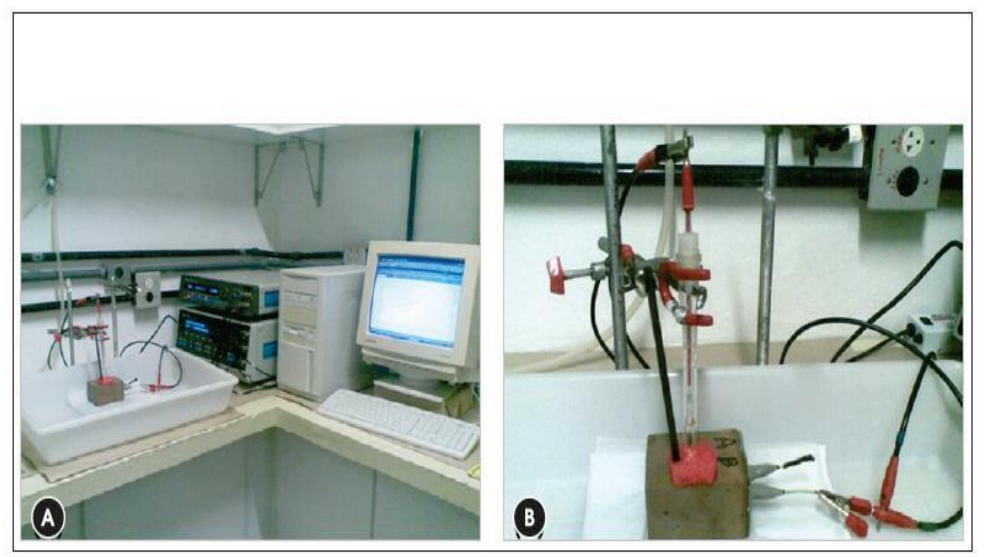

Fig 1 Apparatus used in measuring the corrosion process by electrochemical impedance spectroscopy (EIS)

\section{Results and Discussion}

The results of the study are represented in table 1-7 and figure 2-8.

Table 1. Inhibition efficiency for aspartic acid as corrosion inhibitor of mild steel

\begin{tabular}{ccccc}
\hline Conc & \multicolumn{4}{c}{ Percentage Inhibition efficiency } \\
/ppm & $301 \mathrm{~K}$ & $305 \mathrm{~K}$ & $309 \mathrm{~K}$ & $313 \mathrm{~K}$ \\
\hline \multirow{5}{*}{100} & $2.86 \mathrm{w}$ & $3.61 \mathrm{w}$ & $6.36 \mathrm{w}$ & $8.36 \mathrm{w}$ \\
& $10.12 \mathrm{a}$ & $15.47 \mathrm{a}$ & $21.17 \mathrm{a}$ & $27.56 \mathrm{a}$ \\
& $33.00 \mathrm{e}$ & $39.00 \mathrm{e}$ & $45.09 \mathrm{e}$ & $51.96 \mathrm{e}$ \\
& $9.29 \mathrm{w}$ & $10.84 \mathrm{w}$ & $12.29 \mathrm{w}$ & $12.36 \mathrm{w}$ \\
& $27.73 \mathrm{a}$ & $35.76 \mathrm{a}$ & $41.47 \mathrm{a}$ & $46.14 \mathrm{a}$ \\
& $52.14 \mathrm{e}$ & $53.08 \mathrm{e}$ & $55.00 \mathrm{e}$ & $65.00 \mathrm{e}$ \\
& & & & \\
300 & $13.57 \mathrm{w}$ & $16.25 \mathrm{w}$ & $18.22 \mathrm{w}$ & $18.55 \mathrm{w}$ \\
& $44.26 \mathrm{a}$ & $45.91 \mathrm{a}$ & $48.19 \mathrm{a}$ & $55.40 \mathrm{a}$ \\
& $58.13 \mathrm{e}$ & $59.33 \mathrm{e}$ & $60.00 \mathrm{e}$ & $67.33 \mathrm{e}$ \\
& $21.86 \mathrm{w}$ & $23.49 \mathrm{w}$ & $28.81 \mathrm{w}$ & $29.09 \mathrm{w}$ \\
& $51.44 \mathrm{a}$ & $58.93 \mathrm{a}$ & $62.46 \mathrm{a}$ & $65.22 \mathrm{a}$ \\
& $64.50 \mathrm{e}$ & $64.12 \mathrm{e}$ & $65.00 \mathrm{e}$ & $71.18 \mathrm{e}$ \\
& $27.14 \mathrm{w}$ & $28.31 \mathrm{w}$ & $28.89 \mathrm{w}$ & $32.36 \mathrm{w}$ \\
& $56.28 \mathrm{a}$ & $62.72 \mathrm{a}$ & $63.54 \mathrm{a}$ & $66.26 \mathrm{a}$ \\
& $74.23 \mathrm{e}$ & $75.60 \mathrm{e}$ & $74.00 \mathrm{e}$ & $80.40 \mathrm{e}$ \\
\hline
\end{tabular}


Table 2. Corrosion rate and surface coverage for Aspartic acid

\begin{tabular}{|c|c|c|c|c|c|c|c|c|}
\hline \multirow{2}{*}{$\begin{array}{l}\text { Conc } \\
\text { (g/dm3) }\end{array}$} & \multicolumn{3}{|c|}{ Corrosion rate (mgcm-2h-1) } & \multicolumn{5}{|c|}{ Surface Coverage $(\theta)$} \\
\hline & $301 \mathrm{~K}$ & $305 \mathrm{~K}$ & $309 \mathrm{~K}$ & $313 \mathrm{~K}$ & $301 \mathrm{~K}$ & $305 \mathrm{~K}$ & $309 \mathrm{~K}$ & $313 \mathrm{~K}$ \\
\hline Blank & 1.799 & 2.116 & 2.923 & 3.638 & - & - & - & - \\
\hline$\times 10-3$ & 1.081 & 1.362 & 1.622 & 2.034 & - & - & - & - \\
\hline 0.1 & 1.799 & 2.116 & 2.923 & 3.333 & $0.057 w$ & $0.036 w$ & $0.064 w$ & $0.084 w$ \\
\hline \multirow[t]{2}{*}{$\times 10-4$} & 9.713 & 11.51 & 12.79 & 14.74 & $0.101 a$ & $0.155 a$ & $0.212 a$ & $0.276 a$ \\
\hline & & & & & $0.333 \mathrm{e}$ & $0.390 \mathrm{e}$ & $0.451 \mathrm{e}$ & $0.520 \mathrm{e}$ \\
\hline 0.2 & 1.680 & 1.958 & 2.738 & 3.188 & $0.093 w$ & $0.108 w$ & $0.123 w$ & $0.124 w$ \\
\hline \multirow[t]{2}{*}{$\times 10-4$} & 7.810 & 8.750 & 9.498 & 10.96 & $0.277 a$ & $0.358 a$ & $0.415 a$ & $0.461 a$ \\
\hline & & & & & $0.521 \mathrm{e}$ & $0.531 \mathrm{e}$ & $0.550 \mathrm{e}$ & $0.650 \mathrm{e}$ \\
\hline 0.3 & 1.601 & 1.772 & 2.553 & 2.963 & $0.136 w$ & $0.163 w$ & $0.182 w$ & $0.186 w$ \\
\hline \multirow[t]{2}{*}{$\times 10-4$} & 6.024 & 7.368 & 8.407 & 9.076 & $0.443 a$ & $0.459 a$ & $0.482 a$ & $0.554 a$ \\
\hline & & & & & $0.581 \mathrm{e}$ & $0.593 e$ & $0.600 \mathrm{e}$ & $0.673 e$ \\
\hline 0.4 & 1.336 & 1.680 & 2.235 & 2.579 & $0.219 w$ & $0.235 w$ & $0.288 w$ & $0.291 w$ \\
\hline \multirow[t]{2}{*}{$\times 10-4$} & 5.247 & 5.594 & 6.092 & 7.076 & $0.514 a$ & $0.589 a$ & $0.625 a$ & $0.652 a$ \\
\hline & & & & & $0.645 \mathrm{e}$ & $0.641 \mathrm{e}$ & $0.650 \mathrm{e}$ & $0.712 \mathrm{e}$ \\
\hline 0.5 & 1.164 & 1.574 & 2.235 & 2.460 & $0.271 w$ & $0.283 w$ & $0.289 w$ & $0.325 \mathrm{w}$ \\
\hline \multirow[t]{2}{*}{$\times 10-4$} & 4.725 & 5.078 & 5.915 & 6.866 & $0.653 a$ & $0.627 a$ & $0.636 a$ & $0.663 a$ \\
\hline & & & & & $0.742 \mathrm{e}$ & $0.756 \mathrm{e}$ & $0.740 \mathrm{e}$ & $0.804 \mathrm{e}$ \\
\hline
\end{tabular}

$\mathrm{W}=$ weight loss; $\mathrm{a}=$ acidimetry; $\mathrm{e}=$ Electrochemical impedance spectroscopy

Table 3. Apparent Parameters of Kinetic Energy and Thermodynamics for Aspartic acid

\begin{tabular}{|c|c|c|c|c|c|c|c|c|}
\hline \multirow[t]{2}{*}{$\begin{array}{l}\text { Conc. } \\
\mathrm{g} / \mathrm{dm}^{-3}\end{array}$} & \multicolumn{2}{|c|}{$\begin{array}{l}\text { Ea } \\
(\mathrm{kJ} / \mathrm{mol})\end{array}$} & \multirow[t]{2}{*}{$\begin{array}{l}+Q_{\text {ads }} \\
(\mathrm{kJ} / \mathrm{mol})\end{array}$} & \multirow[t]{2}{*}{$\begin{array}{l}+\Delta \mathrm{H}^{*} \text { ads } \\
(\mathrm{kJ} / \mathrm{mol})\end{array}$} & \multicolumn{2}{|l|}{$\begin{array}{c}\Delta \mathrm{S}^{*}{ }_{\text {ads }} \\
(\mathrm{J} / \mathrm{mol})\end{array}$} & \multicolumn{2}{|c|}{$\Delta \mathrm{G}_{\mathrm{ads}}(\mathrm{kJ} / \mathrm{mol})$} \\
\hline & & & & & $301 \mathrm{~K}$ & $305 \mathrm{~K}$ & $309 \mathrm{~K}$ & $313 \mathrm{~K}$ \\
\hline \multirow[t]{2}{*}{ Blank } & 55.46 & - & 49.01 & -93.806 & - & - & - & - \\
\hline & 40.60 & - & 38.05 & -175.31 & - & - & - & - \\
\hline \multirow[t]{2}{*}{0.1} & 42.56 & 3.580 & 40.11 & -107.28 & -6.991 & -7.694 & -9.324 & -10.21 \\
\hline & 26.58 & 9.518 & 24.03 & -222.75 & -10.35 & -11.72 & -12.86 & -13.93 \\
\hline \multirow[t]{2}{*}{0.2} & 44.19 & 3.187 & 41.64 & -102.50 & -8.376 & -8.922 & -9.404 & -9.543 \\
\hline & 21.49 & 6.255 & 18.94 & -241.58 & -11.68 & -12.78 & -13.57 & -14.24 \\
\hline \multirow[t]{2}{*}{0.3} & 43.28 & 3.613 & 40.73 & -106.06 & -8.431 & -9.080 & -9.554 & -9.735 \\
\hline & 26.72 & 3.366 & 24.17 & -226.09 & -12.49 & -12.82 & -13.23 & -14.15 \\
\hline \multirow[t]{2}{*}{0.4} & 44.27 & 2.462 & 41.72 & -103.91 & -9.156 & -9.514 & -10.35 & -10.52 \\
\hline & 19.19 & 4.396 & 16.64 & -252.67 & -12.49 & -13.42 & -13.98 & -14.47 \\
\hline \multirow[t]{2}{*}{0.5} & 50.92 & 2.604 & 48.37 & -82.741 & -9.314 & -9.586 & -9.784 & -10.34 \\
\hline & 24.90 & 3.077 & 22.35 & -234.60 & -12.42 & -13.26 & -13.53 & -14.01 \\
\hline
\end{tabular}


Table 4. Parameters of Linearized adsorption isotherms

\begin{tabular}{cccccccc}
\hline Isotherm & Temp $(\mathrm{K})$ & $\mathrm{R}^{2}$ & Slope & Intercept & $\mathrm{K}$ & $\begin{array}{c}-\Delta \mathrm{G} \text { ads } \\
\left(\mathrm{kJmol}^{-1}\right)\end{array}$ \\
\hline Freundlich & & & & & & & \\
& $301 \mathrm{~K}$ & 0.9899 & 1.3911 & -0.1213 & & 1.3222 & 10.75 \\
& $305 \mathrm{~K}$ & 0.9884 & 1.2979 & -0.1272 & & 1.3403 & 10.93 \\
& $309 \mathrm{~K}$ & 0.9832 & 0.9959 & -0.2035 & & 1.5977 & 11.52 \\
& $313 \mathrm{~K}$ & 0.9652 & 0.8828 & -0.2330 & & 1.7100 & 11.85 \\
El-Awady & & & $\mathrm{y}$ & & & & \\
& $301 \mathrm{~K}$ & 0.9935 & 1.5640 & +0.0522 & & 1.1277 & 10.35 \\
& $305 \mathrm{~K}$ & 0.9947 & 1.460 & +0.0589 & & 1.1452 & 10.53 \\
& $309 \mathrm{~K}$ & 0.9785 & 1.1808 & -0.0017 & & 1.0039 & 10.33 \\
Tempkim & $313 \mathrm{~K}$ & 0.9535 & 1.0764 & -0.0192 & & 1.0452 & 10.57 \\
& & & & & $\alpha$ & & \\
& $301 \mathrm{~K}$ & 0.9305 & 2.7443 & -0.9943 & -3.160 & 9.870 & 15.78 \\
& $305 \mathrm{~K}$ & 0.9611 & 2.7523 & -1.0383 & -3.169 & 10.92 & 16.25 \\
& $309 \mathrm{~K}$ & 0.9242 & 2.6553 & -1.0864 & -3.057 & 12.20 & 16.74 \\
Adejo- & $313 \mathrm{~K}$ & 0.8911 & 2.5092 & -1.0896 & -2.889 & 12.29 & 16.98 \\
Ekwenchi & $301 \mathrm{~K}$ & 0.8753 & 0.1213 & 0.1858 & & 1.534 & 11.12 \\
& $305 \mathrm{~K}$ & 0.9102 & 0.1267 & 0.1990 & & 1.581 & 11.35 \\
& $309 \mathrm{~K}$ & 0.8801 & 0.1303 & 0.2154 & & 1.642 & 11.59 \\
& $313 \mathrm{~K}$ & 0.8297 & 0.1351 & 0.2268 & & 1.686 & 11.81 \\
\hline
\end{tabular}

Table 5. Adsorption Isotherm Parameters of Aspartic acid for Acidimetry

\begin{tabular}{|c|c|c|c|c|c|c|c|}
\hline Isotherm & Temperature & $\mathbf{R}^{2}$ & Slope & Intercept & & $\mathbf{K}$ & $\begin{array}{c}-\Delta \mathrm{G}_{\mathrm{ad}} \\
\left(\mathrm{kJmol}^{-1}\right)\end{array}$ \\
\hline \multirow{5}{*}{ Freundlich } & & & $\mathrm{n}$ & & & & \\
\hline & $301 \mathrm{~K}$ & 0.9588 & 1.0882 & +0.1468 & & 1.402 & 10.90 \\
\hline & $305 \mathrm{~K}$ & 0.9687 & 0.8776 & +0.1072 & & 1.280 & 10.81 \\
\hline & $309 \mathrm{~K}$ & 0.9629 & 0.6925 & +0.0496 & & 1.121 & 10.61 \\
\hline & $313 \mathrm{~K}$ & 0.9690 & 0.5594 & +0.0235 & & 1.056 & 10.59 \\
\hline \multirow[t]{5}{*}{ El-Awady } & & & $y$ & & & & \\
\hline & $301 \mathrm{~K}$ & 0.9848 & 1.5486 & +0.6386 & & 4.351 & 13.73 \\
\hline & $305 \mathrm{~K}$ & 0.9919 & 1.3937 & +0.6781 & & 4.765 & 14.14 \\
\hline & $309 \mathrm{~K}$ & 0.9790 & 1.1886 & +0.6365 & & 4.330 & 14.08 \\
\hline & $313 K$ & 0.9883 & 1.0565 & +0.6519 & & 4.486 & 14.36 \\
\hline Adejo- & & & $b$ & $\mathrm{~K}_{\mathrm{AE}}$ & & & \\
\hline \multirow[t]{4}{*}{ Ekwenchi } & $301 K$ & 0.9828 & 0.4604 & +0.4918 & & 3.103 & 12.88 \\
\hline & $305 \mathrm{~K}$ & 0.9709 & 0.5161 & +0.5709 & & 3.723 & 13.52 \\
\hline & $309 \mathrm{~K}$ & 0.9582 & 0.4961 & +0.5869 & & 3.863 & 13.79 \\
\hline & $313 \mathrm{~K}$ & 0.9820 & 0.4971 & +0.6284 & & 4.250 & 14.22 \\
\hline \multirow[t]{5}{*}{ Tempkin } & & & & & $\alpha$ & & \\
\hline & $301 \mathrm{~K}$ & 0.9916 & 1.4491 & -1.1347 & -1.670 & 13.65 & 16.59 \\
\hline & $305 \mathrm{~K}$ & 0.9930 & 1.4403 & -1.2145 & -1.659 & 16.39 & 17.28 \\
\hline & $309 \mathrm{~K}$ & 0.9794 & 1.5699 & -1.3277 & -1.808 & 21.27 & 18.17 \\
\hline & $313 K$ & 0.9890 & 1.7175 & -1.4793 & -1.978 & 30.15 & 19.32 \\
\hline
\end{tabular}


Table 6 Adsorption Isotherm Parameters of Aspartic acid for EIS

\begin{tabular}{lccccccc}
\hline Isotherm & Temperature & $\mathbf{R}^{\mathbf{2}}$ & Slope & Intercept & $\mathbf{K}$ & $\begin{array}{c}-\Delta \mathrm{G}_{\mathrm{ad}} \\
\mathrm{kJmol}^{-1}\end{array}$ \\
Freundlich & & & & & & & \\
& $301 \mathrm{~K}$ & 0.9754 & 0.4742 & +0.0137 & 1.032 & 10.13 \\
& $305 \mathrm{~K}$ & 0.9815 & 0.3851 & -0.0201 & 1.047 & 10.30 \\
& $309 \mathrm{~K}$ & 0.9793 & 0.2893 & -0.060 & 1.148 & 10.67 \\
El-Awady & $313 \mathrm{~K}$ & 0.9543 & 0.2453 & -0.0338 & & 1.081 & 10.65 \\
& & & $\mathrm{y}$ & & & & \\
& $301 \mathrm{~K}$ & 0.9755 & 1.011 & +0.7098 & & 5.126 & 14.14 \\
Adejo- & $305 \mathrm{~K}$ & 0.9435 & 0.8879 & +0.6719 & & 4.697 & 14.11 \\
Ekwenchi & $309 \mathrm{~K}$ & 0.9352 & 0.7055 & +0.5923 & & 3.911 & 13.82 \\
& $313 \mathrm{~K}$ & 0.9125 & 0.7242 & +0.7477 & & 5.593 & 14.93 \\
& $301 \mathrm{~K}$ & 0.9395 & 0.5371 & +0.6961 & & 4.967 & 14.06 \\
& $305 \mathrm{~K}$ & 0.8884 & 0.5028 & +0.6920 & & 4.920 & 14.22 \\
Tempkin & $309 \mathrm{~K}$ & 0.8909 & 0.4162 & +0.6524 & & 4.492 & 14.17 \\
& $313 \mathrm{~K}$ & 0.8757 & 0.4789 & 0.7814 & & 6.045 & 15.13 \\
& & & & & $\alpha$ & & \\
& $301 \mathrm{~K}$ & 0.9811 & 1.254 & -1.1676 & -1.444 & 14.71 & 16.78 \\
& $305 \mathrm{~K}$ & 0.9792 & 1.701 & -1.490 & -1.959 & 30.90 & 18.88 \\
& $309 \mathrm{~K}$ & 0.9545 & 2.75 & -1.8936 & -3.166 & 78.27 & 21.57 \\
& $313 \mathrm{~K}$ & 0.9795 & 2.2135 & -2.0858 & -2.549 & 121.84 & 22.95 \\
& & & & & & &
\end{tabular}

Table 7. Impedance Parameters for mild steel in $0.5 \mathrm{M} \mathrm{H}_{2} \mathrm{SO}_{4}$

\begin{tabular}{lcccc}
\hline \multicolumn{5}{c}{$305 \mathrm{~K}$} \\
\hline Inhibitor conc $(\mathrm{ppm})$ & $R_{c t}\left(\Omega \mathrm{cm}^{2}\right)$ & $R_{s}(\Omega \mathrm{cm})$ & $C_{d l}\left(\mu \mathrm{Fcm} \mathrm{Cm}^{-2}\right)$ & $\% \eta$ \\
Blank & 610 & 1.69 & 503.94 & - \\
100 & 1000 & 1.70 & 94.95 & 39.00 \\
200 & 1300 & 1.45 & 73.04 & 53.08 \\
300 & 1500 & 1.23 & 63.30 & 59.33 \\
400 & 1700 & 1.34 & 55.85 & 64.12 \\
500 & 2500 & 1.56 & 48.03 & 75.60 \\
\hline & & $309 \mathrm{~K}$ & & \\
Blank & 560 & 1.62 & 271.33 & - \\
100 & 1020 & 1.60 & 240.22 & 45.09 \\
200 & 1250 & 1.46 & 194.49 & 55.00 \\
300 & 1400 & 1.12 & 173.65 & 60.00 \\
400 & 1600 & 1.03 & 94.96 & 65.00 \\
500 & 2200 & 1.25 & 69.06 & 74.00 \\
\hline
\end{tabular}




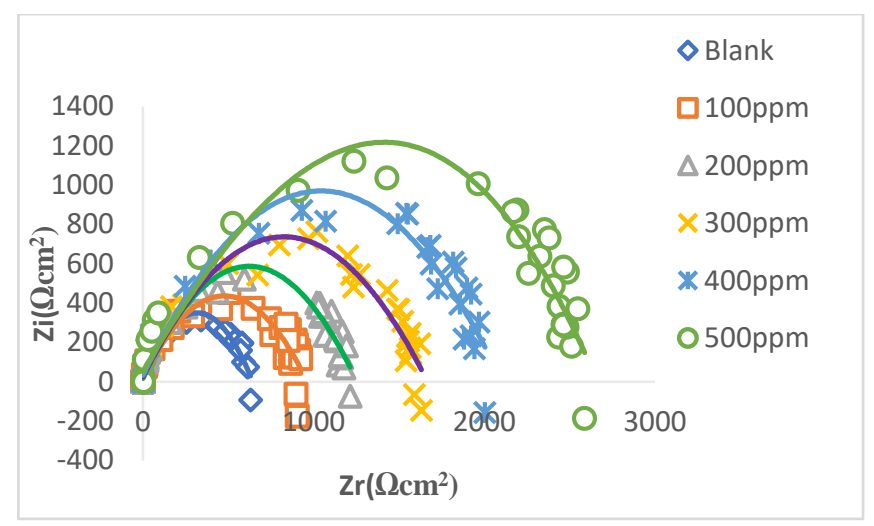

Fig 2 Nyquist plots for mild steel in $0.5 \mathrm{M} \mathrm{H}_{2} \mathrm{SO}_{4}$ at $301 \mathrm{~K}$ in the absence and presence of Aspartic acid at different concentrations

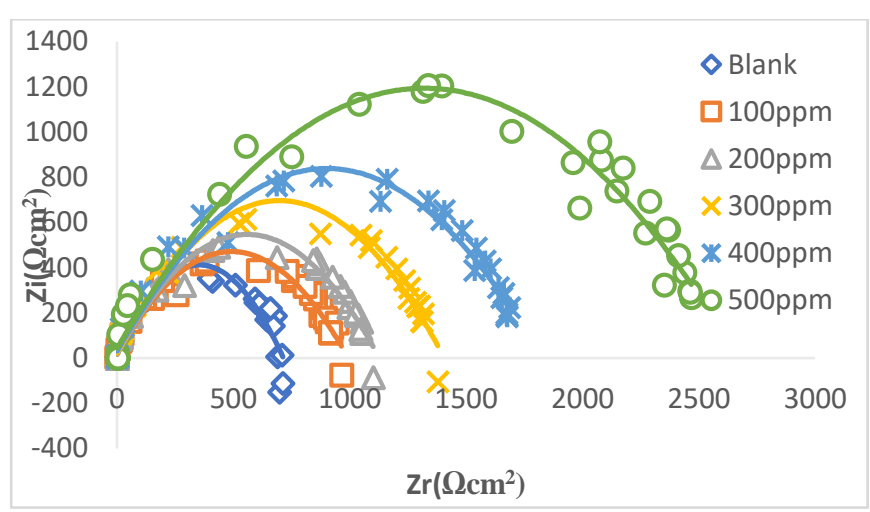

Fig 3 Nyquist plots for mild steel in $0.5 \mathrm{M} \mathrm{H}_{2} \mathrm{SO}_{4}$ at $305 \mathrm{~K}$ in the absence and presence of Aspartic acid at different concentrations

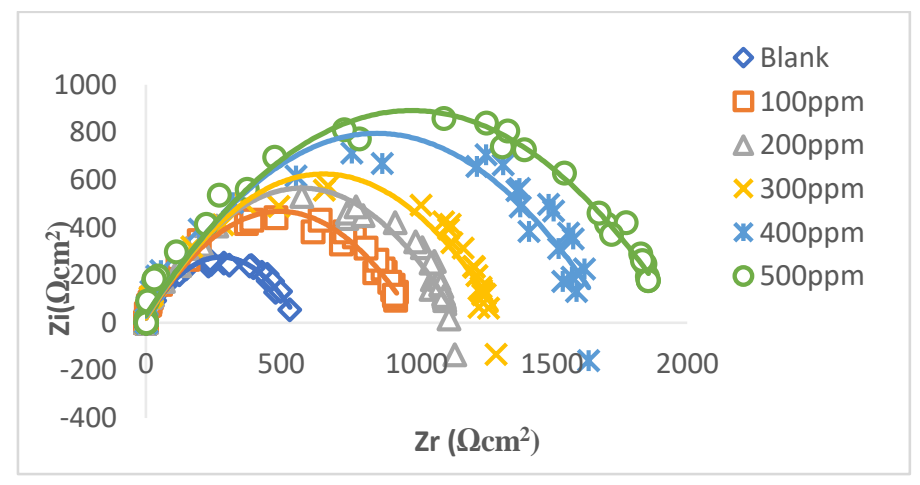

Fig 4 Nyquist plots for mild steel in $0.5 \mathrm{M} \mathrm{H}_{2} \mathrm{SO}_{4}$ at $309 \mathrm{~K}$ in the absence and presence of Aspartic acid at different concentrations 


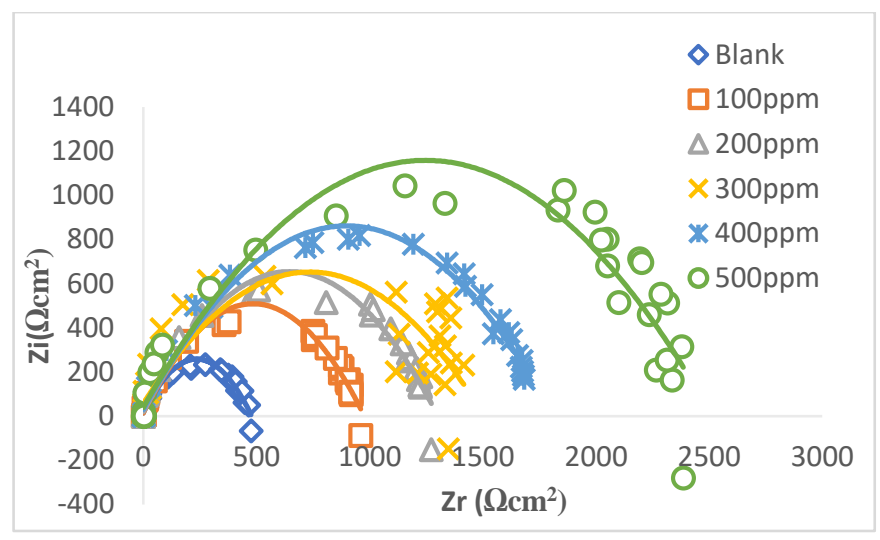

Fig 5 Nyquist plots for mild steel in $0.5 \mathrm{M} \mathrm{H}_{2} \mathrm{SO}_{4}$ at $313 \mathrm{~K}$ in the absence and presence of Aspartic acid at different concentrations

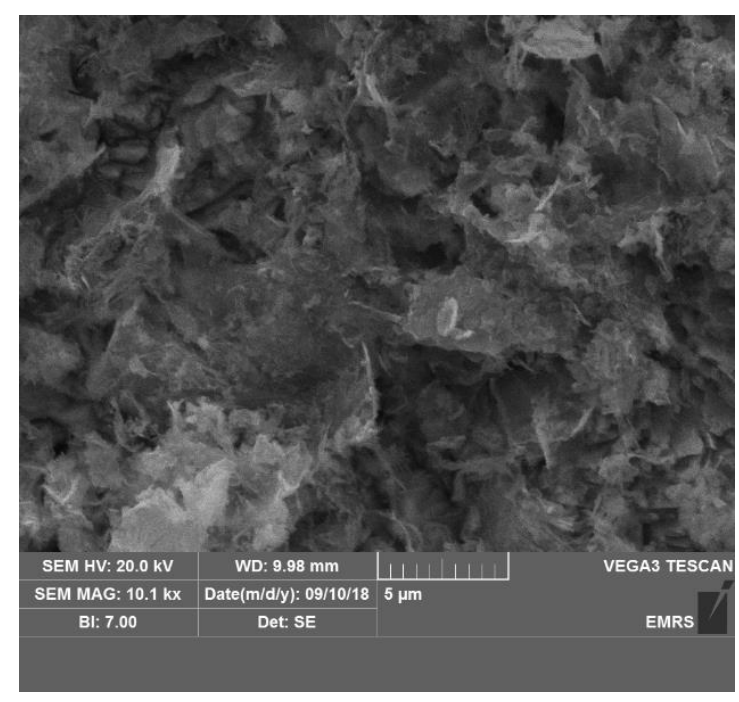

Fig 6 SEM of uninhibited mild steel

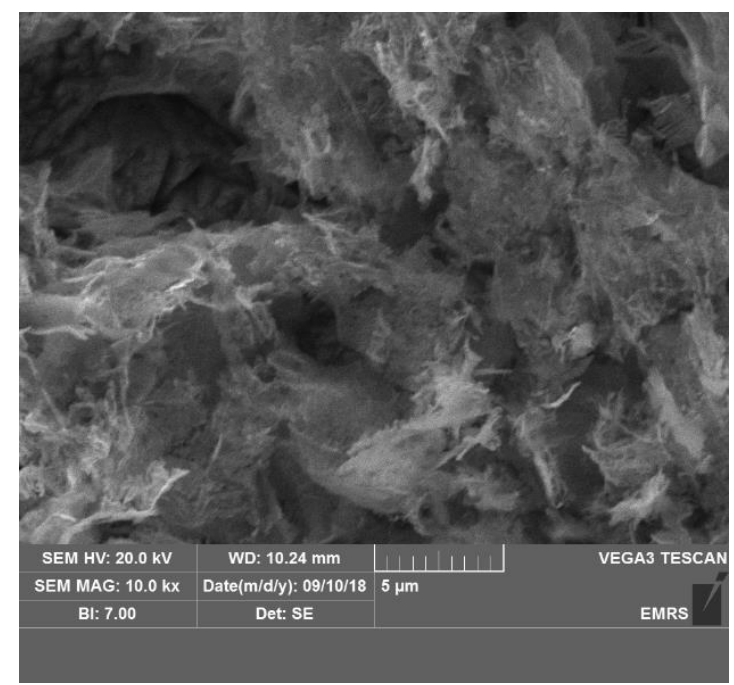

Fig 7 SEM of mild steel surface at 100ppm

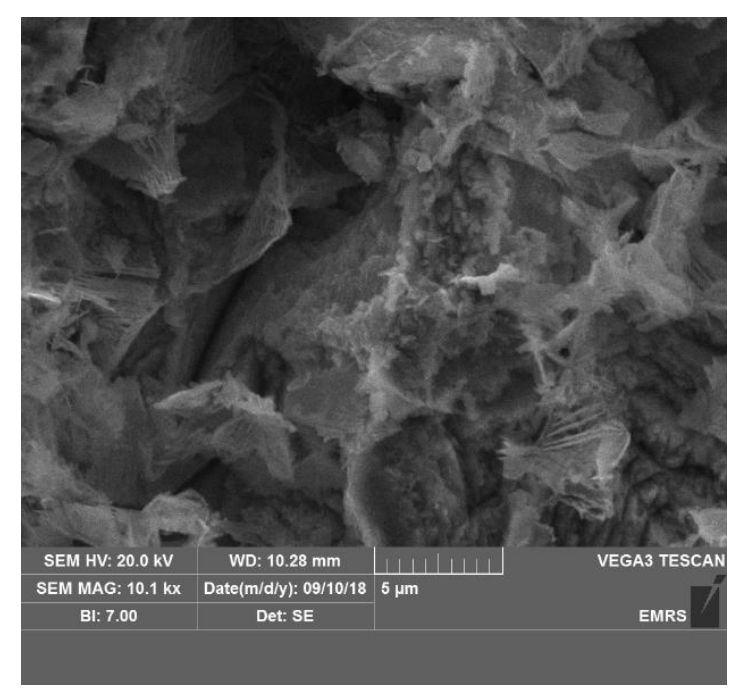

Fig 8 SEM of mild steel coupon at 500ppm 


\section{Discussion}

From the tables, it can be seen that there was a significant difference between values of inhibition efficiency of the inhibitors at $301 \mathrm{~K}$ and $313 \mathrm{~K}$. This increase in inhibition efficiency with rise in temperature could be as a result of chemical adsorption of the inhibiting species onto the metal surface [17].

The high rate of corrosion that was observed to be high in the blank came down with the introduction of the inhibitors into the corroding medium (table 2). Generally, it is clear that the rate of corrosion of mild steel was affected by temperature and concentration of these inhibitors [18-23]. Table 2 showed that corrosion rate decreased with concentration of aspartic acid but was high at higher temperatures while surface coverage increased progressively with rise in both inhibitor concentration and temperature for all the three methods.

Computed values of enthalpy of activation for all the reported methods are positive and lower than that of the blank as shown in table 3 implying that inhibition effectiveness increased with increase in temperature [3,4, 24]. The dissolution process was also endothermic as the values were all positive. The average difference of $E_{a}-$ $\Delta H^{*}$ in equation (14) for weight loss and acidimetry was found to be $2.530 \mathrm{~kJ} / \mathrm{mol}$ and $2.550 \mathrm{~kJ} / \mathrm{mol}$ respectively, approximately same as the value of RT $(2.570 \mathrm{~kJ} / \mathrm{mol})$, where $\mathrm{T}$ is the average of the temperatures (307 K) at which the research was conducted. This implies that the corrosion process of this metal in the acid medium was unimolecular $[8,9]$.

$$
E_{a}-\Delta H^{*}=R T
$$

Values of entropy of activation, $\Delta S_{a d s}^{*}$, are presented in table 3 . The values are all negative indicating that the activated complex in the rate-determining step associative unimolecular, that is a decrease in disorderliness in going from reactants to the activated complex [13, 25-28].

The heats of adsorption for all inhibitors were all positive indicating that the processes were endothermic (table 3). This means an absorption of energy from the surrounding was required for the reaction to be sustained [29].

$\Delta G_{\text {ads }}$ values also presented in tables 3 for the three methods and are all negative and increased with rise in temperature indicating that spontaneity of the adsorption process and stability of absorbed layer increased with rise in temperature for the studied methods. However, the values are below $-20.0 \mathrm{~kJ} / \mathrm{mol}$. Implying physical adsorption mechanism [30-34].

Inhibition of metallic corrosion by additives has been attributed by their adsorption unto the metal surface. This can be confirmed by the fitness of the experimental data into the various adsorption isotherms.

Table 4-6. show the results of fitness of the inhibitors to four isotherms tested, using $R^{2}$ as the basis. These are the Tempkin, Adejo-Ekwenchi, Freundlich and El-Awady, adsorption isotherms [35].

A plot of $\log \theta$ versus $\log C$ gave a straight line with slope equal to $\mathrm{n}$ and intercept $\log K$. The positive adsorption equilibrium constant, $K$, values are indication of favourable adsorption. The parameter, $n$, in the Freundlich isotherm is related to intensity of adsorption and it varies with heterogeneity of the material [4] and the value is always positive but not an integer, with a typical value of 0.60 [14-18]. The values of parameter $n$ are not too close to 0.6 and lower temperatures ( $301 \mathrm{~K}$ and $305 \mathrm{~K}$ ). At $309 \mathrm{~K}$ and $313 \mathrm{~K}$ the values shift close to the typical value of 0.6 an indication that this adsorption process can reasonably be modeled by this isotherm at high temperatures. Values of $\Delta G_{\text {ads }}$ obtained through this isotherm are below $-20 \mathrm{~kJ} / \mathrm{mol}$ for all the inhibitors in both weight loss and acidimetry methods further supporting physical adsorption [4-7].

The adsorption also followed the kinetic model of the El-Awady isotherm. For this isotherm, a plot of $\log \frac{\theta}{1-\theta}$ versus $\log C$ also gave a straight line with slope of $y$. Values of $y$ from table 4-6 are consistently greater than 1 for all the methods meaning a multilayer adsorption with El-Awady model.

The value of parameter $b$ in the Adejo-Ekwenchi isotherm obviously resolves the argument of whether an inhibitor is physically or chemically adsorbed. Decrease in $b$ value with rise in temperature signifies physisorption, while increase or fairly constant value indicates chemisorption. From Tables 4-6 it is obvious that the adsorption of the plant extract onto the metal surface is chemical adsorption as $b$ increases with rise in 
temperature. The values of $\Delta$ Gads obtained through this isotherm are close to those other isotherms and has compared well with those obtained through the conventional method [4-7].

Tempkin isotherm better models chemisorption. The negative sign of parameter $\alpha$ of the isotherm is an indication of repulsive interaction of molecules within the adsorbed layer. The adherence to this isotherm of the adsorption process of the inhibitors indicates that the adsorption process is chemisorption, a fact which is supported by increase in inhibition efficiency with rise in temperature and in agreement with the Adejo-Ekwenchi adsorption isotherm [34]

The corrosion inhibition of mild steel in $0.5 \mathrm{M} \mathrm{H}_{2} \mathrm{SO}_{4}$ was investigated by EIS method after immersion for 7 hours. The locus of the Nyquist plots is regarded as one part of a semicircle. Nyquist plots of mild steel in inhibited and uninhibited acidic solutions containing various concentrations of the inhibitor are shown in Fig 2-5. The impedance diagrams obtained are not perfect semicircles as expected by the theory of EIS. This could be attributed to frequency dispersion and the non-ideal behaviour of double layer as a capacitor [17]. Fortunately, it effectively indicated that the charge transfer resistance of the blank in all studied systems were lower than that of the inhibited samples [15].

The charge transfer resistance Rct, was got from the diameter of the semicircle; To obtain the double layer capacitance, $C_{d l}$ the frequency at which the imaginary component of the impedance is maximum, $f\left(-Z_{\max }\right)$ was found, and $C_{d l}$ values were obtained from equation 4.10. below

$f\left(-Z_{\max }\right)=\frac{1}{2 \pi C_{d l} R_{c t}}$

where, $R_{c t}$ is the charge transfer resistance.

The impedance parameters derived from this investigation are given in Table 7. It was found that as the concentration of the inhibitors increased the Rct values also increased but the values of $C_{d l}$ tend to decrease. The decrease in the $C_{d l}$ values is due to the adsorption of the inhibitor on the metal surface. Generally, values of corrosion potential shift towards the positive direction when the concentration of the inhibitors increase $[8,19]$. This observation is indicative of the anodic type control of corrosion inhibition and an inhibition of this type acts mainly as an anodic type inhibitor. According to the study undertaken by EIS, we can establish that the more the charge transfer resistance increased the more the adsorption of the adsorbent on the metal surface [17].

Surface features of the studied coupons $2.0 \times 2.0 \times 0.35 \mathrm{~cm}$ were examined using scanning electron microscope after exposure to $0.5 \mathrm{M} \mathrm{H}_{2} \mathrm{SO}_{4}$ for $7 \mathrm{~h}$ with and without the inhibitors at $305 \mathrm{~K}$. The highest and lowest studied concentration was considered and the depth of the corrosion pits as shown in figures 6-8 were compared.

Fig 6 has the highest depth of corrosion pits which is the coupon that was not inhibited. In figures 7 and 8 , the pits appeared shallower which is a suggestion that the inhibitor molecules were adsorbed on the surface thus hindering the corrosion process and is better at 500 ppm [30].

\section{Conclusion}

Aspartic acid inhibited corrosion of mild steel coupons at $301 \mathrm{~K}, 305 \mathrm{~K}, 309 \mathrm{~K}$ and $313 \mathrm{~K}$ with good inhibition efficiencies. The established methods of monitoring corrosion were used as control to check the efficacy of acidimetry. The corrosion inhibition of the coupons in $0.5 \mathrm{M} \mathrm{H}_{2} \mathrm{SO}_{4}$ solution was found to be a function of the inhibitor concentration and temperature. The inhibition efficiencies increased with increase in temperature and the activation energy increased with increase in concentration, characteristic of chemical adsorption mechanism, the value of $\Delta G_{\text {ads }}$ for for all the isotherms were below $-20 \mathrm{~kJ} / \mathrm{mol}$ but with the $A E l$ it was resolved to be chemical adsorption.

\section{Conflicts of Interest}

Authors declare conflicting interests exist.

\section{Acknowledgements}

We acknowledge the contribution of Petroleun Technology Development Fund (PTDF) Abuja, Nigeria for sponsoring the research work. 


\section{References}

[1] Adejo, S. O., Ekwenchi, M. M., Momoh, F. and Odiniya, E. (2012). Adsorption characterization of ethanol extract of leaves of Portulaca oleracea as green corrosion inhibitor for corrosion of mild steel in sulphuric acid medium. International Journal of Modern Chemistry, 1(3), 125-134.

[2]. Adejo, S. O., Yiase, S. G., Ahile, U. J., Tyohemba, T. G. and Gbertyo, J. A. (2013). Inhibitory effect and adsorption parameters of extract of leaves of Portulaca oleracea of corrosion of aluminium in $\mathrm{H}_{2} \mathrm{SO}_{4}$ solution. Archives of applied science research, 5(1), 25-32.

[3]. Adejo, S. O. (2014). Proposing a new empirical adsorption isotherm known as Adejo-Ekwenchi isotherm. IOSR, Journal of Applied Chemistry, 2014, 6 (5), 66-71. doi, 10, 5736-0656671.

[4]. Adejo, S. O., Gbertyo, J. A. and Ahile, J. U. (2013). Inhibitive properties and adsorption consideration of ethanol extract of Manihot esculentum leaves for corrosion inhibition of aluminium in $2 \mathrm{M}$ $\mathrm{H}_{2} \mathrm{SO}_{4}$. International Journal of modern chemistry, 4(3), 137-146.

[5]. Adejo, S. O., Ekwenchi, M. M., Odiniya, E. O., Acholo, J. P. and Banke, S. P. (2010). Ethanol extract of leaves of Portulaca oleracea as green inhibitor for corrosion of mild steel in $\mathrm{H}_{2} \mathrm{SO}_{4}$ medium. Proceedings of the International Conference on Research and Development Accra, Ghana, 113-118.

[6]. Adejo, S. O., Ekwenchi, M. M., Gbertyo, J. A., Menenge, T. and Ogbodo, J. O. (2014). Determination of adsorption Isotherm model best fit for methanol leaf extract of Securinega virosa as corrosion inhibitor for corrosion of mild steel in $\mathrm{HCl}$. Journal of Advances in Chemistry, 10(5).

[7]. Adejo, S. O., Ekwenchi, M. M. and Banke, S. P. (2010). Ethanol extract of leaves of Manihot esculentum as eco-friendly inhibitor for corrosion of mild steel in $\mathrm{H}_{2} \mathrm{SO}_{4}$ medium. Proceedings of the 33rd Annual Intrtnational Conference of Chemical Society of Nigeria, Osun, 240-244.

[8]. Camila G. Dariva and Alexandre F. Galio (2014). Corrosion Inhibitors - Principles, Mechanisms and Applications, Developments in Corrosion Protection, Dr. M. Aliofkhazraei (Ed.), InTech, DOI: 10.5772/57255. Available from: https://www.intechopen.com/books/developments-in-corrosionprotection/corrosion-inhibitors-principles-mechanisms-and-applications

[9]. Liu, F., Zhang, L., Yan, X., Lu, X., Gao, Y. and Zhao, C. (2015). Effect of diesel on corrosion inhibitors and application of bio-enzyme corrosion inhibitors in the laboratory Cooling water system. Corrosion Science, 93, 293-300.

[10]. Umoren, S. A., Obot, I. B., Madhankumar, A. and Gasem, Z. M. (2015). Performance evaluation of pectin as ecofriendly corrosion inhibitor for X60 pipeline steel in acid medium: experimental and theoretical approaches. Carbohydrate polymers, 124, 280-291.

[11]. Tiu, B. D. B. and Advincula, R. C. (2015). Polymeric corrosion inhibitors for the oil and gas industry: design principles and mechanism. Reactive and Functional Polymers, 95, 25-45.

[12]. Hasanov, R. Bilge, S. Bilgic, S. Gece, G Kılıc, Z. (2010). Experimental and theoretical calculations on corrosion inhibition of steel in $1 \mathrm{M} \mathrm{H}_{2} \mathrm{SO}_{4}$ by crown type polyethers. Journal of Corrosion Science, 52, 984-990.

[13]. Anupama, K. K., Ramya, K., Shainy, K. M. and Joseph, A. (2015). Adsorption and electrochemical studies of Pimenta dioica leaf extracts as corrosion inhibitor for mild steel in hydrochloric acid. Materials Chemistry and Physics, 167, 28-41.

[14]. Zeigler, E. S. (1914). Corrosion of common metals and methods of prevention. Naval Engineers Journal, 26(3), 854-863.

[15]. Bentissa, F., Lagreneea, M., Traisnel, M., Hornez, J. C. (1999) The corrosion inhibition of mild steel in acidic media by a new triazole derivative, Corrosion Science 41, 789-803

[16]. Tourabi, M., Sahibed-Dine, A., Zarrouk, A., Obot, I. B., Hammouti, B., Bentiss, F., and Nahlé, A. (2017). 3, 5 Diaryl-4-amino-1, 2, 4-triazole derivatives as effective corrosion inhibitors for mild steel in hydrochloric acid solution: Correlation between anti-corrosion activity and chemical structure. Protection of Metals and Physical Chemistry of Surfaces, 53(3), 548-559

[17] Umoren, S. A., Eduok, U. M., Solomon, M. M. and Udoh, A. P. (2016). Corrosion inhibition by leaves and stem extracts of Sida acuta for mild steel in $1 \mathrm{M} \mathrm{H}_{2} \mathrm{SO}_{4}$ solutions investigated by chemical and spectroscopic techniques. Arabian journal of chemistry, 9, S209-S224.

[18]. Faustin, M., Maciuk, A., Salvin, P., Roos, C. and Lebrini, M. (2015). Corrosion inhibition of C38 steel by alkaloids extract of Geissospermum leave in $1 \mathrm{M}$ hydrochloric acid: Electrochemical and phytochemical studies. Corrosion Science, 92, 287-300. 
[19]. Odewunmi, N. A., Umoren, S. A. and Gasem, Z. M. (2015). Watermelon waste products as green corrosion inhibitors for mild steel in $\mathrm{HCl}$ solution. Journal of Environmental Chemical Engineering, 3(1), 286-296.

[20]. Fiori-Bimbi, M. V., Alvarez, P. E., Vaca, H. and Gervasi, C. A. (2015). Corrosion inhibition of mild steel in HCL solution by pectin, Corrosion Science, 92, 192-199.

[21]. Saidia, N., Elmsellema, H., Ramdania, M., Chetouania, A., Azzaouib, K. and Yousfia, F. (2015). Using pectin extract as eco-friendly inhibitor for steel corrosion in $1 \mathrm{M} \mathrm{HCl}$ media. Der PharmaChemica, 7(5), 87-94.

[22]. Ji, G., Anjum, S., Sundaram, S. and Prakash, R. (2015). Musa paradisica peel extract as green corrosion inhibitor for mild steel in $\mathrm{HCl}$ solution. Corrosion Science, 90, 107-117.

[23]. Chaussemier, M., Pourmohtasham, E., Gelus, D., Pécoul, N., Perrot, H., Lédion, J. and Horner, O. (2015). State of art of natural inhibitors of calcium carbonate scaling. A review article. Desalination, 356, 47-55.

[24]. Alaneme, K. K., Daramola, Y. S., Olusegun, S. J. and Afolabi, A. S. (2015). Corrosion inhibition and adsorption characteristics of rice husk extracts on mild steel immersed in $1 \mathrm{M} \mathrm{H}_{2} \mathrm{SO}_{4}$ and $\mathrm{HCl}$ solutions. International Journal of Electrochemical Science, 10, 3553-3567.

[25]. Odewunmi, N. A., Umoren, S. A. and Gasem, Z. M. (2015). Utilization of watermelon rind extract as a green corrosion inhibitor for mild steel in acidic media. Journal of Industrial and Engineering Chemistry, 21, 239247.

[26]. Umoren, S. A., and Solomon, M. M. (2015). Effect of halide ions on the corrosion inhibition efficiency of different organic species- a review. Journal of Industrial and Engineering Chemistry, 21, 81-100.

[27]. El Hamdani, N., Fdil, R., Tourabi, M., Jama, C. and Bentiss, F. (2015). Alkaloids extract of Retama monosperma (L.) Boiss. seeds used as novel eco-friendly inhibitor for carbon steel corrosion in $1 \mathrm{M} \mathrm{HCl}$ solution: Electrochemical and surface studies. Applied Surface Science, 357, 1294-1305.

[28]. Kumar, A. and Bashir, S. (2015). Review on Corrosion inhibition of Steel in Acidic media. International Journal of ChemTech Research, 8(7), 391-396.

[29]. Victoria, S. N., Prasad, R. and Manivannan, R. (2015). Psidium guajava leaf extract as green corrosion inhibitor for mild steel in phosphoric acid. International Journal of Electrochemical Science, 10, 2220-2238.

[30]. Umoren, S. A., Obot, I. B. and Gasem, Z. M. (2015). Adsorption and corrosion inhibition characteristics of strawberry fruit extract at steel/acids interfaces: experimental and theoretical approaches. lonics, 21(4), 1171-1186.

[31]. Ejikeme, P. M., Umana, S. G., Menkiti, M. C. and Onukwuli, O. D. (2015). Inhibition of Mild Steel and Aluminium Corrosion in $1 \mathrm{M} \mathrm{H}_{2} \mathrm{SO}_{4}$ by Leaves Extract of African Breadfruit. International Journal of Materials and Chemistry, 5(1), 14-23.

[32]. Alaneme, K. K., Olusegun, S. J. and Adelowo, O. T. (2016). Corrosion inhibition and adsorption mechanism studies of Hunteria umbellata seed husk extracts on mild steel immersed in acidic solutions. Alexandria Engineering Journal, 55(1), 673-681.

[33]. Odewunmi, N. A., Umoren, S. A., Gasem, Z. M., Ganiyu, S. A. and Muhammad, Q. (2015). L-Citrulline: An active corrosion inhibitor component of watermelon rind extract for mild steel in $\mathrm{HCl}$ medium. Journal of the Taiwan Institute of Chemical Engineers, 51, 177-185.

[34]. Mihajlović, M. B. P. and Antonijević, M. M. (2015). Copper Corrosion Inhibitors. Period 2008-2014. A Review, International Journal of Electrochemical Science, 10, 1027-1053.

[35]. Bentissa, F., Lagreneea, M., Traisnel, M., Hornez, J. C. (1999) The corrosion inhibition of mild steel in acidic media by a new triazole derivative, Corrosion Science 41, 789-803 